\title{
Performance-Based Building: Architecture of an Integrated Model at Conceptual and Practical Dimensions
}

\author{
Serkan Arslan \\ Civil Engineer, M.Sc. \\ Istanbul Technical University, Institute of Science and Technology, \\ Project and Construction Management PhD Program, Istanbul \\ Alaattin Kanoglu \\ Ph.D., Professor \\ Istanbul Technical University, \\ Faculty of Architecture, Istanbul
}

\begin{abstract}
Traditional building production process is a multi-phased and multi-stakeholder process which is fragmented too much in many aspects. Naturally, the process of production which has already difficulties due to reasons such as disconnections among the organizations which is included in the process during transitions between phases and which undertake various responsibilities in each phase, missing project documentation, conflicts of interests of the stakeholders and similar reasons becomes even more complicated and the output of this process is also often problematic. While the clients, who makes the basic decisions, forms the product and the process to maximize their profit, the end user especially in underdeveloped countries is victimized due to the inadequacy of legal regulations, lack of information on the standard performance values which the product has to provide, weakness of the mechanisms to protect the interests of the community in design and construction processes to overcome these deficiencies in addition to reluctance to meet the cost of individually needed expert support and what's more, losses occur at national and global scales, resources are wasted and problems as to sustainable development arise. The traditional construction process which while trying to minimize the first investment cost, causes increasing life cycle cost to high levels stands out as a structure for which particularly developing countries have to rethink of and develop alternative models. At this point, Performance-Based Building phenomena seems to draw more attention as a solution. This study aims to discuss the above stated approach as well as structure and tools which support this approach with all of its dimensions at conceptual levels and define the architecture of the model required to transfer them to practice at conceptual and practical dimensions.
\end{abstract}

Keywords: Competition, innovation, information systems, interoperability, performance based building.

\section{INTRODUCTION}

The difficulty as to change and transformation of established structures, which show resistance to every kind of development and innovation, is at obvious; however, existence and sustainability of life are not safe in places where these transformations cannot be achieved. Social consciousness, like it does in many issues, finds ways for solution thanks to general education and knowledge level even if it's late; however, it is not possible to affect the decisionmaking mechanisms as to public auditing and realize these transformations by the efforts of individual initiatives or weak non-governmental organizations in non-organized less developed countries. On the other hand, quantity of demand as much as its quality, is also very important in pressures and directions required for these transformations, and in addition to 
individuals or companies, the entire construction sector needs to evolve into a new perspective on this issue.

\section{BASIC DIMENSIONS OF THE SOLUTION AND MODEL PROPOSED}

Construction of a rational model in order to solve the identified problem is only possible with a comprehensive study to be conducted with involvement of a two-staged and concurrent multiple studies of numerous teams. The first stage is the identification of a new philosophical approach for basing the project procurement process on a ground which is different than the structure of the traditional approach and consequently identification with the main lines of a conceptual model be set forth in line with this. The conceptual model should address and define the components of the solution in the following dimensions:

(i) Philosophical/Paradigmatic Model

(ii) Process-Related/Organizational Model

(iii)Computational/Evaluation Model

(iv)Integration/Interoperability Model

(v) Computer/Software Model

\section{Philosophical/Paradigmatic Model: Re-thinking Construction and a Production Process Focusing on Sustainability and Interoperability}

A philosophical approach which provides living space for sustainable design and building approaches instead of a structure which is left to individual expectations, interests and initiatives of individual entrepreneurs. This philosophy must adopt the approach that global resources are our common heritage and all deeds and actions should also take care of the rights of future generations. This philosophy also must adopt innovative approaches which focuses on extending competition to entire building production process instead of limiting it within the tender process and bid-price strategies. Thus, it will be possible to transform the role of the architect into a design professional who does not act in line with the desire of the entrepreneur but who protects the longterm benefits of the society within the context of competition by design. The paradigmatic components of the cited approach must be a new process and organizational model which internalizes the concepts of innovation, competitiveness, integration and interoperability.

\section{Organizational/Process-Related Model: Re-thinking Shareholders, Their Functions and Relationships throughout the Building Production Process}

Redefinition of fundamental principles in terms of process and organization of an alternative approach to eliminate the issues created through traditional project delivery approaches as well as the identities and roles of stakeholders and their relations must be the main subject of a study which aims to solve it.

The basic functions in such an approach and the identification of institutional structures which will undertake these functions and their relations should be included on the basis of a model proposal for performance-based building (PBB). The roles, powers and responsibilities of the stakeholders in the process should be defined and transactions required by the functions at each stage and the methods and data for calculation should also be defined, if any, while this structure of the process is defined.

It will be correct to start by identifying the steps which make up the process of the PBB approach. Unlike traditional project procurement approach, in PBB approach a client enters into agreement with a design office and rejects the advantage of reducing the cost of the building from the beginning by obtaining the design of the building and by making the contractors who will require to produce this product to compete on this product. On the 
contrary, the client must identify the expectations thereof as to the product based on their performance values and reveal them to be presented to potential contractors.

In this process, a preliminary project can be used with a design which does not contain any recommendation at the level of building components and composite elements, or a process in which proposed design documents and projects are prepared separately by each contractor in competition without taking into consideration any limitation but local codes and regulations.

In this process each contractor has to prepare a design which will meet all measurable expectations of client at the levels of (1) component, (2) element, (3) subsystem, (4) premise, (5) building and (6) settlement, identified through key performance indicators (KPIs) and submit their bid prices. Naturally this approach will not provide the easiness of a comparison which can be made on one single identified product and bid prices proposed for it. And just for this reason in this approach where different designs subject to the bid price cannot be compared in terms of form and content, weighted key performance indicators that are at the core of performance-based building and all comparisons with scoring methods based on these indicators. That is exactly why, in PBB approach in which different design documents and bid prices are submitted cannot be compared with each other in terms of form and content and there is an obligation of making all comparisons by weighted scores as to alternative solutions by means of weighted key performance indicators which are the essence of performance-based building and scoring methods based on these indicators.

Testing and approval procedures, which can be performed through accredited laboratories for the components included within the physical structure of the building, are valid for the tangible entities/systems/components related to performance in product dimension. However, one of the basic proposals of the developed model is that to only measure the performance of the physical components which constitute the product would be incomplete; in other words, process-related entities/systems/components should also be taken into consideration in performance calculations. When two separate teams with different levels of experience produce the same structural components on construction site during the construction process, their possibility to obtain different performance results is very high. As such, it is an inevitable necessity to include the effect of the process into the calculation in addition to the product for determination of general performance as to production.

It is obvious that this process described hereinabove, cannot be put into practice without obtaining technological infrastructure which can respond to the usual speed of the bidding and tendering processes of the construction projects. As such, structuring of the cited data sets and obtaining comparable unified bids is essential both in order to see the effect of performance value to the total score when a component selected from the component library used while the 3D design is being developed and for prompt evaluation of bids by the client right after these bids are submitted.

The conceptual model developed in this study suggests the coordination of specialized competent bodies/specialty groups in evaluation, auditing, testing and documenting entities of different types, such as materials, organizations, and processes as well as establishment of a data/information processing system which calculates the performance levels of these entities relatively. While it may be possible to objectively evaluate the performance of tangible entities such as materials, components, building elements and etc. which constitute the building the difficulties as to evaluating the performance of organizations such as subcontractors, suppliers and vendors. However, quality assurance systems seem to bring a partial solution to this part of the problem. Studies as to evaluation of these organizations and participants at the 
conceptual level are already found in professional practice and literature. Minchin, and Smith [1], Elyamany, et.al., [2], Oyedele and Tham [3], Doolen and et.al., [4] have proposed their own models for performance-based evaluations of contractors, architects, and suppliers who are participants of the building production process which can be used within the context of quality assurance systems.

The structure related to the process proposed under the model is provided in Figure 1 and Figure 2 in the light of all these explanations. 


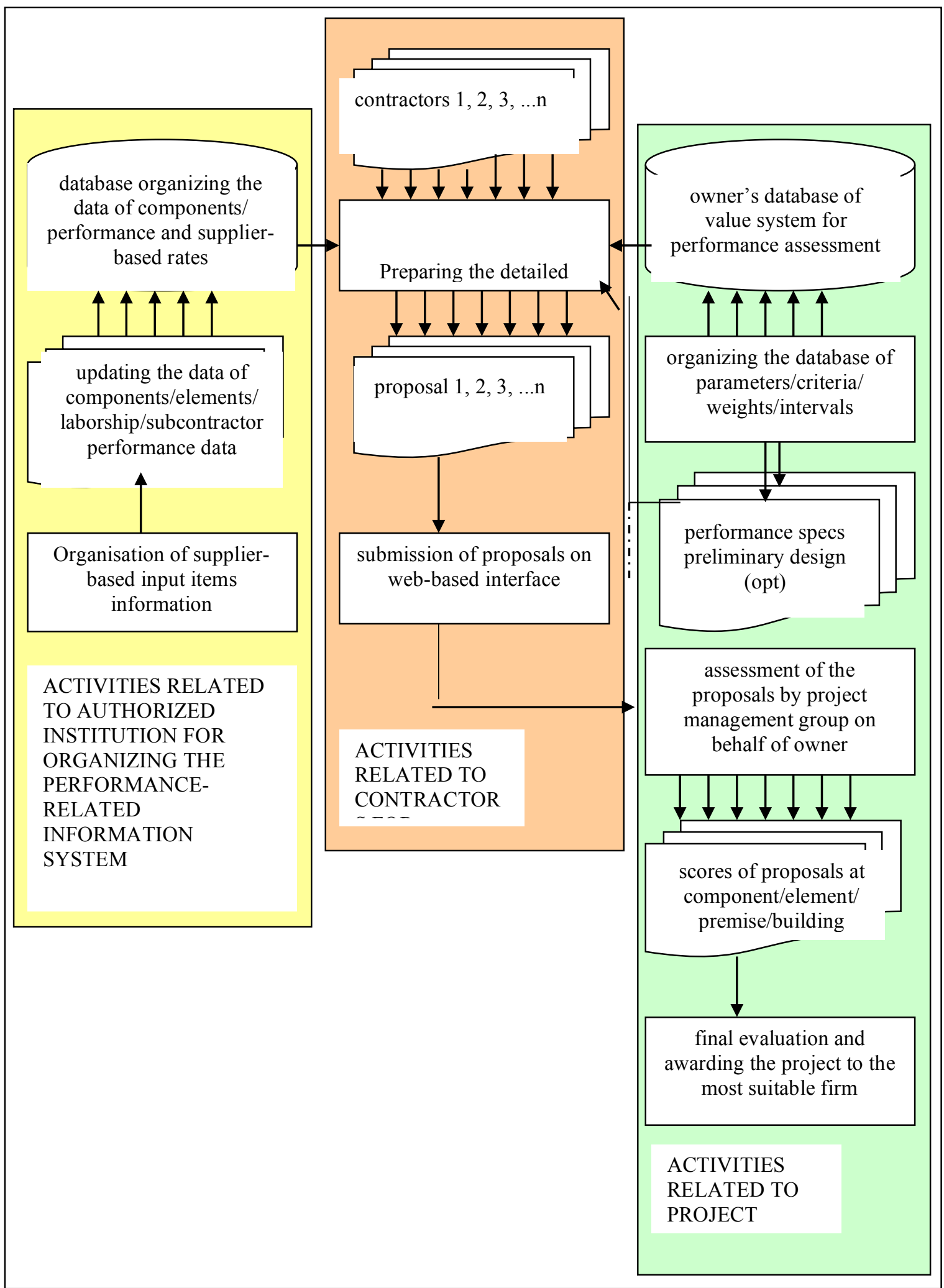

Figure 1. Diagram incident to relation between basic functions, shareholders and roles as regards the suggested performance-based building process, and stakeholders 


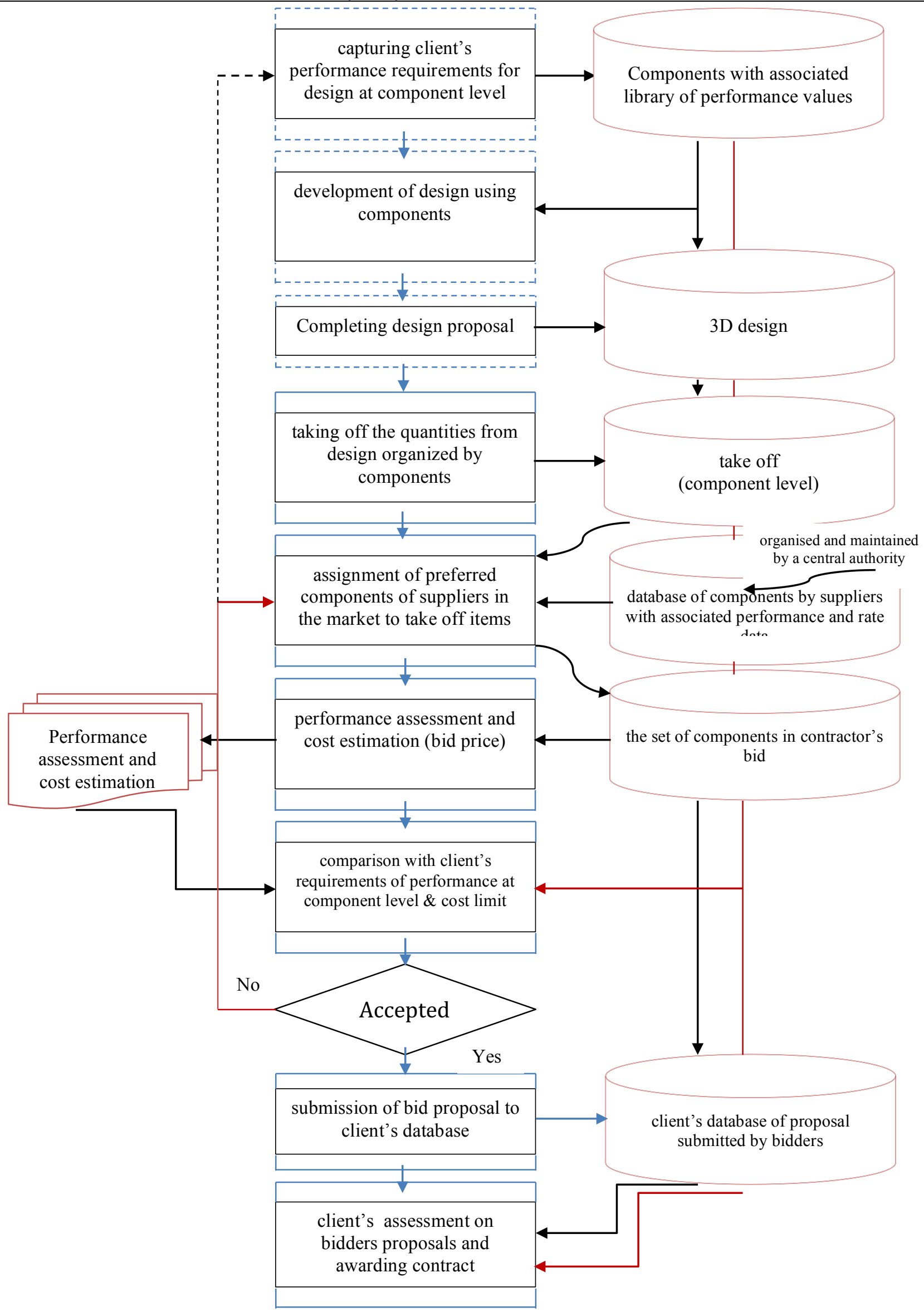

Figure 2. Process related model 
It is highly probable that traditional and innovative systems are in need of different types of organizational and information system structures. If practical models are not proposed on these issues, the construction industry will continue to employ traditional and conventional models and will resist new solutions. When the organizational aspect of the performancebased approach is evaluated, the approach proposed in this study which proposes the delegation of authority to a number of specialized bodies will help to solution only up to a specific level inasmuch as the performance parameters of components in the type of material/equipment/labor can be measured by the authorized bodies accredited through a central authority. Evaluations in terms of premises forces the client to reconfigure its own project organization in a way to involve project groups specialized in evaluation and reporting of related parameters/subsystems such as noise control, fire protection, heating, lighting and etc. The construction industry must seek solutions which will overcome such organizational difficulties with a view to benefit from the advantages of innovative approaches.

It is necessary to identify the stakeholders needed for the operation of the process described hereinabove and define the relations between them, and their authorities and responsibilities in order to understand the proposed model. The stakeholders which have to undertake various roles in the process in order that the model functions successfully and their roles are listed and explained below.

\section{Client (Entrepreneur/Investor/Individual Owner/Public Authority)}

The clients are the driving force behind the construction industry in the general sense inasmuch as they are both the initiators and the financiers of the construction process. Understanding the expectations and requirements of a client who has such an important place in the industry completely and reflecting it in the project design is extremely important in terms of both client satisfaction and success of the project.

There is a need for a client who prefers a performance-based approach for procurement of the project so that the proposed model can work successfully. As long as the lack of a regulations which makes the performance-based approach mandatory for the private or public sector and the required informatics infrastructure it will not be possible for private entrepreneurs or public authorities to prefer performance-based approach in their projects. Enacting encouraging legislations for the implementation of this approach which currently would not be desired by the industry of its own accord/voluntarily for various reasons seems essential for the applicability of the model.

\section{Construction Firm}

Construction firms have to give a proposal to the project put out to tender in line with the preference of the client or according to the preliminary design or from scratch in the tender organized by the client even without any preliminary design by revealing the performance expectations thereof as to only the components/elements/ subsystems/premises/building and settlement levels in the proposed model. As such, unlike traditional building production and project procurement systems and approaches, there is also the benefit of this organization to work with a team of experts consisting of experienced designers and specialists who will accurately assess the basic expectations of the client and direct the design.

\section{Design Firm}

Oyedele and Tham [3] have measured importance of the criterion by representing the intention of the client on an intention measure and determined the intention of the client on the criterion in their study made for measuring success of the architect by looking with the client's eye after the delivery of the building. 
One of the most significant functions of the architect is to provide the client with accurate information and it has been reported that many architects are careless in this regard. The first stage of design is an accurate identification of needs. The sensitivity that the architect will show in receiving information from the client reflects his ability on the issues of understanding the client's corporate objectives, having a vision as to the requirements of the users and evaluating them, determining the project targets as well as the order of importance thereof and complying with the business owner's requirements through analyzes of design concepts and requirements.

One of the most fundamental and indispensable roles in the proposed model belongs to the design firms. 'Competition by design' concept constitutes one of the fundamental axes of the proposed model. The architectural and engineering offices which realize the design of all subsystems of the building have to develop their designs which meet the performance values to fulfill the expectations of the client together with the expert groups involved in the organization of the contractor. In this context, there is a need for designers conducting works to develop components which will achieve equivalent performance with innovative attitude to increase the 'competitive advantage' of the construction industry, adopting new components/technologies and following the possibilities provided by a strong research/development sector adequately.

\section{Research and Development Firms}

'Innovativeness' constitutes one of the fundamental axes of the proposed model. In the global system, the role of consumption is mostly attributed to institutions and organizations in third world countries and therefore emergence of an industry which can compete with the products of other companies at global level in these countries requires the support of research and development activities and the organizations which realizes the said through correct and effective incentive models. One of the most essential requirements for designers is to put into practice the concept of competition by design by including innovative products and processes in their designs and thus contribute to the competitiveness of the solutions in bid packages of the contractors in the project procurement process. It is a fundamental requirement to put into practice the legislative regulations safeguarding intellectual property rights of the products developed in parallel.

\section{Manufacturing Firms}

Inasmuch as manufacturers affect the final performance of the production, they are the most important key part of the chain [4,5]. Companies which are part of global competition have revealed the fact that cooperating with suppliers brings a 'competitive advantage' for construction companies. The presence of the manufacturer firms which can provide the components and technologies, developed and patented by the research and development (R\&D) firms, by developing effective production systems in the most economical way for usage is indispensable for the success of the proposed model. It is essential for these firms to create a feedback system which will be obtained from professional practice for the development of the quality of manufactured components and maintain a strong mutual relation with contractors, design firms and, if necessary, with R\&D firms in the field of technology and product development by virtue of the information obtained through the CRM - Customer Relationship Management software and ISO 9000 Quality Assurance System.

\section{Accredited Labs}

These companies have to be present in the sector with qualified infrastructure and staff in order that new products and technologies produced by R\&D companies are developed and for the realization of testing/validation/ certification processes. 
While the testing and approval processes of the product, i.e., the components included in the building's physical structure, are provided through the accredited laboratories, the testing/approval/certification process for other non-physical elements of the technology and production process must be provided through another mechanism. The model proposed in this section suggests that a score section for components should be added to the reports produced as a result of the evaluation studies carried out for stakeholder organizations in the context of ISO 9000 Quality Assurance Systems. In this way, the score to be received as a result of the ISO 9000 evaluation process, can be reflected on the effect thereof on the overall performance of the project and in the performance evaluation calculations as regards the level of positive effect of each company, subcontractor, designer, supplier and etc. will have on the process. As mentioned in the previous section, a calculation method integrating the product and process performance values in the project performance calculation is also one of the main starting points of the proposed model.

\section{Information Providers}

Companies, which collect, record and present information to usage or briefly organize these values incident to products and technologies of all R\&D firms which acquire components that will constitute the basis of the scoring system that will allow comparative evaluation in the design and bid evaluation process which are key performance indicators by the test/approval/certification of an accredited firm, constitute one of the keystones of the model. Information provider companies, in a sense, act as the showcase of the manufacturer companies which convey the 3D models of their products in the form defined by the BIM Building Information Modeling codes via internet to designers and which aim to increase their visibility and market share in this way.

Presenting the visual and technical data of the products of the manufacturer companies to the use of the designers and the evaluation groups through these firms will create the difficulty of collecting data from different web pages where these data are dispersed. The solution for this will be special information providers which bring together data dispersed to different environments and present data set including the entire integrated data set to designers and other stakeholders. It can be recommended that a public institution to fulfill this task by undertaking functions such as updating the product test/approval certificates in addition to these data of products with certain intervals instead of this fragmented structure.

\section{Computation Model: Re-thinking Calculation of Performance and Related Entities}

The main subject of this study is determination of need for different types of databases to organize the data required for performance evaluations at different levels, dealing with these databases with organizational structures, organization and approval thereof by acquiring them.

Different databases are needed for organization of the data required for performance evaluations at different levels. Structured and standardized data at the level of components related to materials, components, labor and equipment use and expert teams during the design and construction processes must be organized through a single authorized and central entity. These kinds of inputs should be determined and approved through accreditation and certification bodies and submitted to the applicant firm and the central institution. The database must contain an appropriate and updated list of the parameters (KPIs) utilized in order to measure the performance of each of the above mentioned input items. Information which has to be organized by the system is up-to-date unit price data supplied by manufacturer or vendor which has to be provided to bidders to be used in cost estimation process. These 
scores for these entries at the component level should be determined by the relevant accredited inspection and certification institutions.

Another issue as regards the calculation part is the calculation method. Kashiwagi [6] recommends 'Replaced Ideal Model' which is a modified version of 'Relative Distance Model' (RDM) in multi-criteria decision making process. The widely used 'Analytical Hierarchy Process' (AHP) model utilized frequently for computation is also a valid approach. However, discussions and evaluations as regards the computational model will be discussed in another study in relation to this conceptual work.

The solution for the problem discussed is not the kind which can be realized by individual efforts to be performed at firm or project level; we need radically re-identified, new groundbreaking structural changes, new perspectives and models at the national and/or global dimensions and sector level. There is not a new calculation model developed under the proposed model; an appropriate structure which allow the usage of one or more of the approaches in the literature will be adopted.

\section{Integration Model: Re-thinking Integration of Building Production Process Using BIM 6D at Conceptual and Practical Dimensions}

The search for innovative approaches and possibilities for the integration of organizational and information flow aspects of building production process, which is fragmented in terms of process and stakeholder relationships in traditional practice, must be one of the main subject of the model aiming solution.

Project owners are expected to share their goals and expectations with the designers at the design phase. Contractors should understand how to resolve these requirements and prepare their designs and proposals in a way to meet these expectations. Furthermore, project owners have set up their own value systems in a way as to constitute an input to the design at the project procurement stage in order that designers can understand what is important and acceptable for the employer and they should be allowed to develop an innovative design which contributes to the 'competitive advantage' and 'competition by design' qualifications of the bid packages. What's more this integration also eliminates the consistency issues of what is declared as a requirement by the client/owner and what are applied in the design and procurement processes.

The losses of the construction sector are important due to the multi-phased, fragmented structure of the building production process and lack of communication among the stakeholders. As such, any approach suggested should have an answer to this issue. Information technology's support in addition to organizational solutions such as design-build approach, is also essential for models in this area. Accordingly, although much detail is not provided here, it must be ensured that all tools and models for integration are in place for this fiction.

It is possible to approach the issue from many different directions and intersections and in addition to the presence of integration models addressing the entire construction processes such as the models reported by Kanoglu and Arditi [7], there are also studies trying to integrate design and construction processes like the models reported by Alptekin and Kanoglu [8], and those trying to integrate design and operating processes such as the models reported by Ercoskun and Kanoglu [9] in addition to models developed for kitchens at building premises level reported by Yazıcıoglu and Kanoglu [10, 11, 12, 13, 14, 15]. Similarly, this study has a perspective which integrates design and project procurement processes. 
Thus, communication problems both between the phases of the entire building production process and the various stakeholders involved in these phases will be eliminated while validity, continuity, consistency and transparency of the decisions taken by the client as well as parameters, weights and value system which are essential for the project will be ensured during the project procurement process.

The conceptual model developed within the scope of the study suggests to coordinate specialized agencies to evaluate, inspect, test and document different types of components, such as materials, organizations and processes, and operate a data processing system which provides the relative performance of these assets. Much as performance of tangible assets like materials, building materials and etc. have to be objectively evaluated, the difficulties for evaluating the performance of stakeholders such as subcontractors, material suppliers and vendors are also obvious.

It is clear that realization of the process related to the proposed model which is described hereinabove cannot be accomplished without the support of an information technology that enables the calculation and evaluation processes to be carried out in the design and project procurement processes in a short time and in a practical manner, by taking into consideration the speed required in realization of the projects in the construction sector. Standardization required achieving the quality of interoperability of the entities which make up the whole system and the information produced thereby and again an exemplification can also be provided on this platform.

It is focused on the inclusion of various perspectives when key performance indicators (KPI) are determined. The performance criteria have to cover 4 perspectives: Client perspective, internal business (or activity) perspective, innovation and learning perspective and financial perspective. Performance measures have to be objective, reliable, and timely in addition to using criteria to ensure a balanced view of performance $[4,16]$. Performance criteria must be based on reliable data which cannot be distorted $[4,17]$. In other words, members in the organization must understand the link between the performance criteria and the requested performance targets $[4,18]$. In addition, if effective performance measures will be utilized to determine how current performance will affect the performance in future, then the criteria should be guiding signs rather than being a retrospective indicator $[4,19]$.

Creation of a software which will not be weak compared to the advantages of familiarity to established and accustomed processes in implementing traditional methods, which will suggest fast, practical, and easy to implement processes and which utilize technological opportunities which will support them and which will seek solutions to the issues of consistency and clarity that can lead to reliability problems that can occur during the process.

The support of information technologies is essential not only for enhancing practical convenience, but also for addressing the issues of consistency and explicitness/clarity/intelligibility which can lead to reliability problems that can arise during the process. Obtaining and updating the data required for performance-based evaluations requires web-based, Building Information Modeling (BIM) supported database services in coordination with a central authority. A performance-based evaluation model for the integration of project design and project procurement processes in order to integrate the conceptual model and to put it into practice, is still under development within the context of several research projects/ doctorate theses and this is subject of another article following this study. The studies being conducted currently to this end are carried out with subprojects progressing coordinately within the context of various levels and components under the 
"Master Research Project" entitled "Increasing the Global Competitiveness \& Interoperability of Turkish Construction Industry by Adopting Sustainable Development Policies in Industry 4.0 Era" Kanoglu et.al. [20]. The master project started at 2010 and some modules (subprojects) is completed, some of them are ongoing and some of the modules will be started in a short time. The final product of these studies is the IDEPRO software model and each and every research project under the master project stated above is structured to take a module of final model. Some sample screen snapshots of the IDEPRO_C (Performance-Based Model for the Integration of Design and Project Procurement Processes at Component Level) are given in Figure 3-6. This module of database currently includes approximately 200 tables, 400 queries, 600 forms, 200 reports and 400 macro type objects.

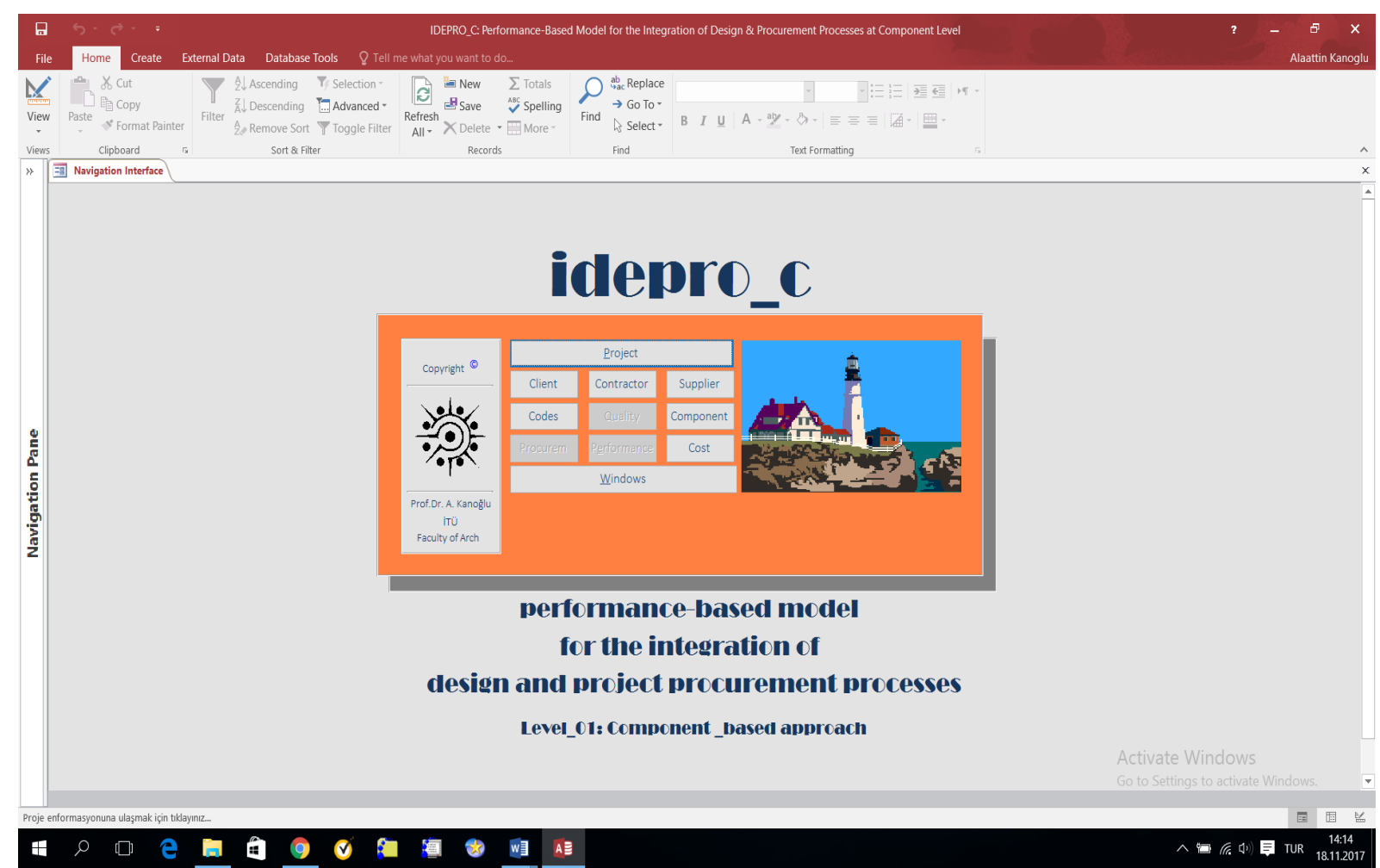

Figure 3. IDEPRO Software Model: Startup User Interface 


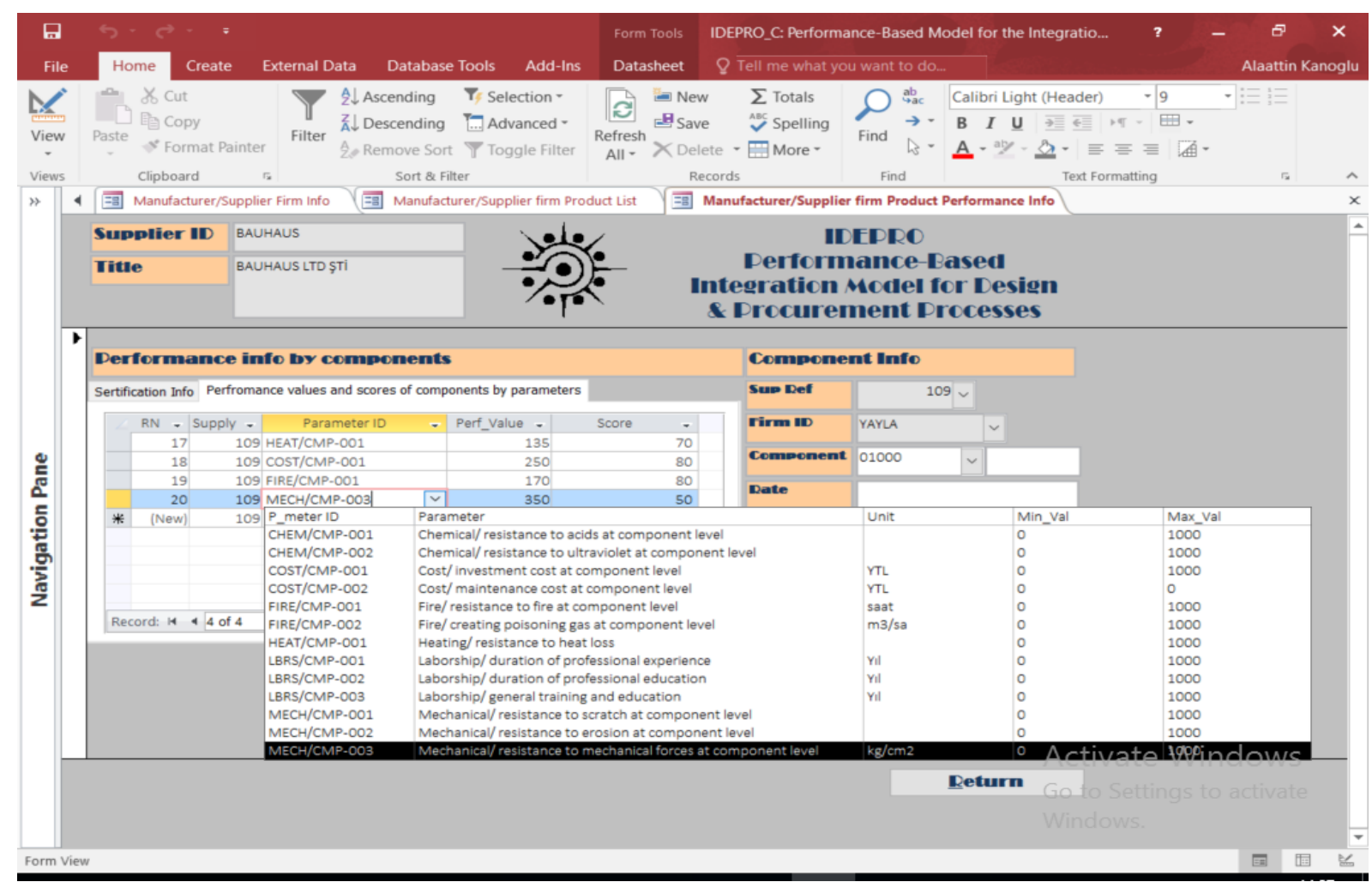

Figure 4. Manufacturer-based performances of components by key performance indicators

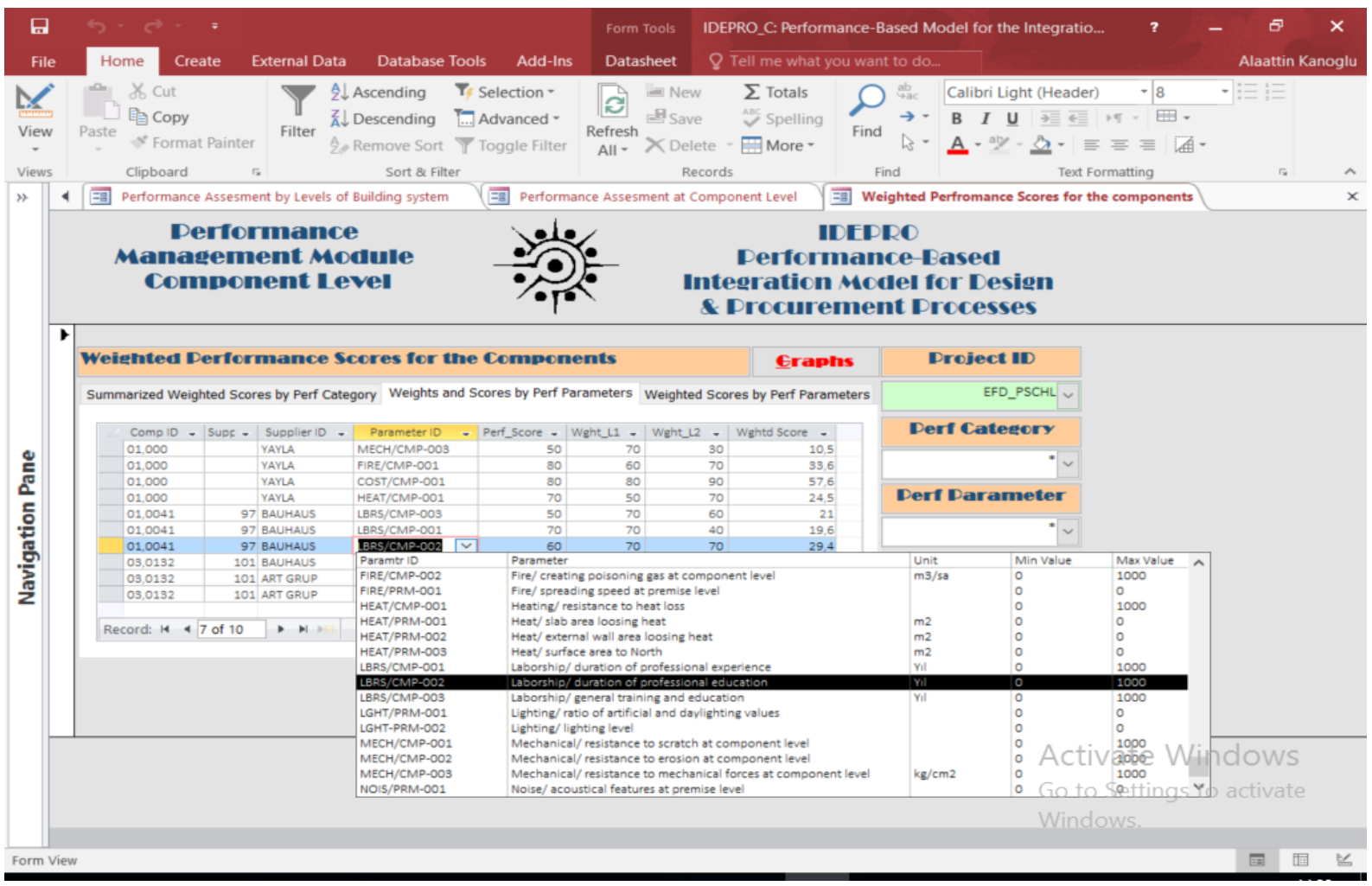

Figure 5. Calculation of weighted performances of components in constructor's proposal 


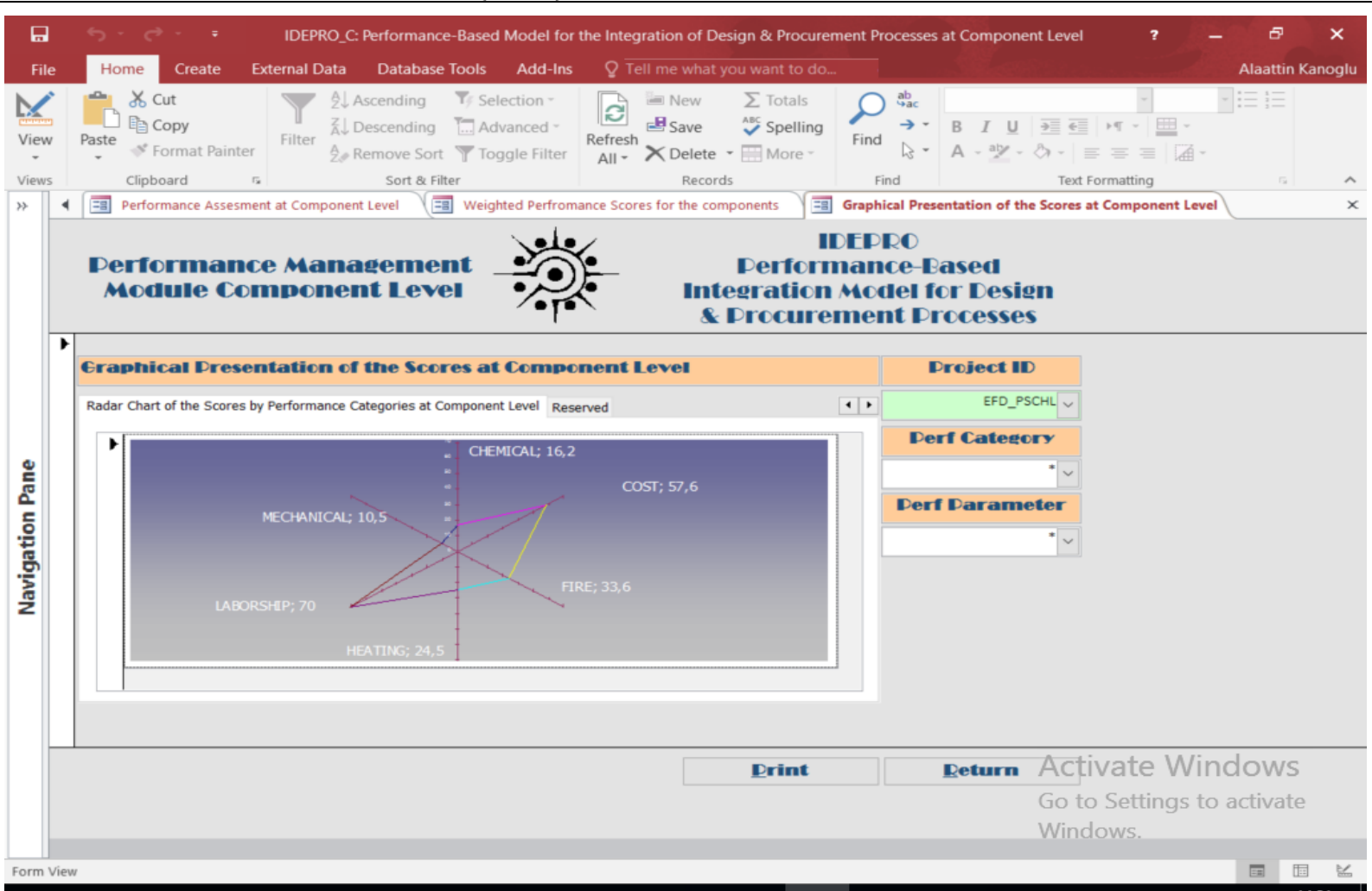

Figure 6. Radar diagram of project proposal's performance by first level parameters

\section{CONCLUSIONS}

It was tried to examine the structure and relation of an integrated model which entrepreneurs operating in the construction sector need in order to fulfill their functions for project procurement at conceptual dimension and reveal the main axes thereof in this study. In order that performance-based approach can have the opportunity to be applied in a significant part of the industry as a valid and effective approach, studies which include all the necessary dimensions for examining all aspects thereof at a sufficient level and transferring them into practice is required. This study is intended to make a contribution to steps as to the cited target.

\section{References}

Minchin, R.E., and Smith, G.R., (2005). "Quality-Based Contractor Rating Model for Qualification and Bidding Purposes", Journal of Management in Engineering, Vol. 21, No. 1, 38-43.

Elyamany, A., Basha, I., and Zayed, T., (2007). "Performance Evaluating Model for Construction Companies: Egyptian Case Study", Journal of Construction Engineering and Management, Vol. 133, No.8, 574-581.

Oyedele, L.O., and Tham K.W., (2007). “Client's Assessment of Architects' Performance in Building Delivery Process: Evidence from Nigeria”, Building and Environment, Vol. 42, 2090-2099.

Doolen, T, Traxler, M., and McBride, K., (2006). “Using Scorecards for Supplier Performance Improvement: Case Application in a Lean Manufacturing Organization”, Engineering Management Journal, Vol. 18, No. 2, $26-34$.

Babineaux, F. M., (2002). Measuring Supplier Performance: How to Get What You Measure and Other Unintentional Consequences, Institute for Supply Managements 87th Annual International Supply Management Conference and Educational Exhibit.

Kashiwagi, D., (1999). The construction delivery system of the information age, Automation in Construction, Vol.8, p. 417-425.

Kanoglu, A., and Arditi, D., (2004). "An Integrated Automation System for Design/Build Organizations", International Journal of Computer Applications in Technology, Indersience Publishers, Vol. 20, No. 1-3, 3-14.

Alptekin, G.O., and Kanoglu, A., (2003) “A Computer-Based Feedback Model for Design/Build Organizations”, ISEC02 - 2nd International Structural Engineering and Construction Conference, Organized by University of Rome, Italy, 23-26 September, 2221-26. 
Ercoskun, K., and Kanoglu, A., (2003) "Client Relationships Management in AEC Sector", 20th International Conference on Information Technology for Construction, Organized by CIB W78 Auckland, New Zealand, 17-19 April, 129-136.

Yazicioglu, D.A., and Kanoglu, A., (2015) "Enhancement of the Designer Performance in Kitchen Interior Design", Advances in Social Sciences Research Journal, Vol. 2, No. 6, 1-8.

Yazicioglu, D.A., and Kanoglu, A., (2016) "Determining Effects of Kitchen Design Rules on Kitchen Functionality in A Comparative Way", Academic Research International, Vol. 7, No. 3, 25-44.

Yazicioglu, D.A., and Kanoglu, A., (2016) "A Systematic Approach for Increasing the Success of Kitchen Interior Design within the Context of Spatial User Requirements", Advances in Social Sciences Research Journal, Vol. 3, No. 1, 155-166.

Yazicioglu, D.A., and Kanoglu, A., (2016) "Improving the Project Service Performance of Companies Producing and Marketing Kitchen Systems to Provide Sectoral Competitiveness", International Journal of Sciences: Basic and Applied Research, Vol. 26, No. 2, 18-27.

Yazicioglu, D.A., and Kanoglu, A., (2016) "Performance-Based Automation System for Kitchen Interior Design", Advances in Social Sciences Research Journal, Vol.3, No.13, 27-45

Yazicioglu, D.A., and Kanoglu, A., (2017) "Improving the Project Service Performance of Companies Producing and Marketing Kitchen Systems: Stage of Survey and Analysis of the Space", International Journal of Advanced and Applied Sciences, Vol.4, No. 2., 139-146.

Kaplan, R.S., and Norton, D.P., (1996). Balanced Scorecard as Strategic Management System, Harward Business Review, Vol. 74, No. 1, pp. 75-85.

Lefkowith, D., (2001). What Gets Measured Gets Done: Turning Strategic Plans into Real World Results, Management Quarterly, Vol.42, No.2 p. 20-24.

Brooks, W.K., and Coleman, G.D., (2003). Evaluating Key Performance Indicators Used to Drive Contractor Behavior at AEDC, Engineering Management Journal, Vol.15, No.4, pp 29-39.

Youngblood, A.D., and Terry, R.J., (2003). Addressing Balanced Trade-off Issues between Performance Metrics Using Multi-Attribute Utility Theory, Engineering Management Journal, Vol.15, No.1, pp11-17.

Kanoglu, A., Arslan., S., Altındağ, M., Yazicioglu, D.A., Özçevik, Ö., Ercoskun, K., (2010) Increasing the Global Competitiveness \& Interoperability of Turkish Construction Industry by Adopting Sustainable Development Policies in Industry 4.0 Era, Master Research Project, https://www.researchgate.net/project/Increasing-theGlobal-Competitiveness-Interoperability-of-Turkish-Construction-Industry-by-Adopting-SustainableDevelopment-Policies-in-Industry-40-Era. 